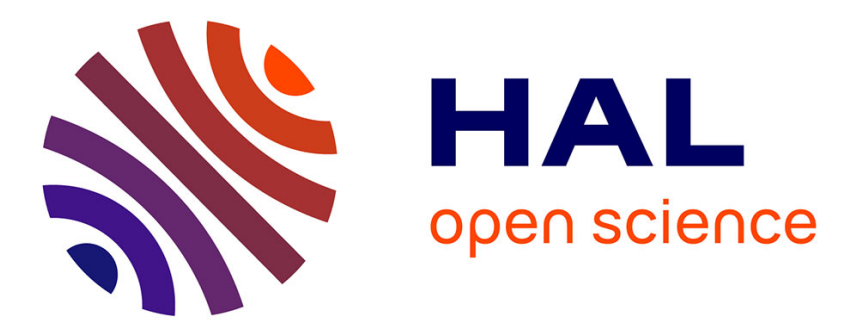

\title{
Quantitative electrophysiological monitoring of anti-histamine drug effects on live cells via reusable sensor platforms
}

Viet Anh Pham Ba, Dong-Guk Cho, Daesan Kim, Haneul Yoo, Van-Thao Ta, Seunghun Hong

\section{To cite this version:}

Viet Anh Pham Ba, Dong-Guk Cho, Daesan Kim, Haneul Yoo, Van-Thao Ta, et al.. Quantitative electrophysiological monitoring of anti-histamine drug effects on live cells via reusable sensor platforms. Biosensors and Bioelectronics, 2017, 94, pp.707-713. 10.1016/j.bios.2017.03.063 . hal-02147137

\section{HAL Id: hal-02147137 \\ https://hal.science/hal-02147137}

Submitted on 4 Jun 2019

HAL is a multi-disciplinary open access archive for the deposit and dissemination of scientific research documents, whether they are published or not. The documents may come from teaching and research institutions in France or abroad, or from public or private research centers.
L'archive ouverte pluridisciplinaire HAL, est destinée au dépôt et à la diffusion de documents scientifiques de niveau recherche, publiés ou non, émanant des établissements d'enseignement et de recherche français ou étrangers, des laboratoires publics ou privés. 
1 Quantitative Electrophysiological Monitoring of Anti-histamine Drug

\section{Effects on Live Cells via Reusable Sensor Platforms}

3 Viet Anh Pham Ba ${ }^{a}$, Dong-guk Cho ${ }^{a}$, Daesan Kim ${ }^{b}$, Haneul Yoo ${ }^{a}$, Van-Thao Ta ${ }^{c}$, Seunghun

$4 \quad$ Hong $^{\mathrm{a}, \mathrm{b}, *}$

$5 \quad{ }^{a}$ Department of Physics and Astronomy and Institute of Applied Physics, Seoul National

6 University, Seoul 08826, Korea

$7 \quad$ b Department of Biophysics and Chemical Biology, Seoul National University, Seoul 08826,

$8 \quad$ Korea

$9{ }^{\mathrm{c}}$ Department of Chemistry, Hanoi National University of Education, Hanoi, Vietnam

$10 *$ Corresponding author at: Department of Physics and Astronomy and Institute of Applied

11 Physics, Seoul National University, Seoul 08826, Korea

12 E-mail address: seunghun@snu.ac.kr 
1 ABSTRACT: We demonstrated the quantitative electrophysiological monitoring of histamine

2 and anti-histamine drug effects on live cells via reusable sensor platforms based on carbon

3 nanotube transistors. This method enabled us to monitor the real-time electrophysiological

4 responses of a single HeLa cell to histamine with different concentrations. The measured

5 electrophysiological responses were attributed to the activity of histamine type 1 receptors on a

6 HeLa cell membrane by histamine. Furthermore, the effects of anti-histamine drugs such as

7 cetirizine or chlorphenamine on the electrophysiological activities of HeLa cells were also

8 evaluated quantitatively. Significantly, we utilized only a single device to monitor the responses

9 of multiple HeLa cells to each drug, which allowed us to quantitatively analyze the antihistamine

10 drug effects on live cells without errors from the device-to-device variation in device

11 characteristics. Such quantitative evaluation capability of our method would promise versatile

12 applications such as drug screening and nanoscale bio sensor researches.

13 Keywords: Anti-histamine; HeLa cell; Carbon nanotube transistor; Reusable sensor 


\section{1. Introduction}

2 Histamine, which acts as a neurotransmitter in central nervous systems, can influence

3 many biological processes such as neuronal excitation and immune regulation via the activation

4 of histamine receptors on cell plasma membranes (Akdis and Blaser, 2003; Benarroch, 2010;

5 MacGlashan, 2003; Schneider et al., 2002). One type of the histamine receptors is histamine type

61 receptor (H1R) which belongs to the family of G-protein-coupled receptors. The activation of

$7 \quad$ H1Rs by histamine triggers many intracellular electrophysiological signaling pathways including

8 the increase of intracellular calcium ions $\left(\mathrm{Ca}^{2+}\right)$ by the opening of $\mathrm{Ca}^{2+}$ channels in a cell plasma

9 membrane (Benarroch, 2010; Jutel et al., 2009; Molina-Hernandez et al., 2012). In non-excitable

10 cells such as HeLa cells, the stimulation of H1Rs embedded in the cell membrane generates the

11 rise of cytosolic free $\mathrm{Ca}^{2+}$ concentrations (Barajas et al., 2008). By measuring the changes of

$12 \mathrm{Ca}^{2+}$ concentrations as well as a $\mathrm{Ca}^{2+}$ influx into cells, the electrophysiological effects of

13 histamine and anti-histamine drugs could be evaluated. In order to quantitatively monitor the

$14 \mathrm{Ca}^{2+}$ influx into the cells, sensitive and reliable measurement techniques are required.

15 The effects of histamine and anti-histamine drugs have been studied extensively using

16 various methods such as fluorescence assays and electrophysiological techniques. Conventional

17 fluorescence assays are simple and have been utilized extensively to evaluate the histamine and

18 antihistamine drug effects (Bootman et al., 1992; Sauve et al., 1991). However, the fluorescence

19 signals of dyes would be degraded over time, which made it very difficult to achieve the

20 quantitative evaluation of drug effects. In addition, the fluorescence assays need

21 time-consuming processes such as the pretreatment of samples with fluorescent dyes.

22 Meanwhile, electrophysiological tools such as patch clamp techniques and nanoscale devices

23 have exhibited outstanding performances in the detection of electrophysiological signals of live 
1 cells stimulated by histamine (Negulyaev Yu et al., 1993; Sauve et al., 1991). The patch clamp

2 methods exhibit high temporal and spatial resolution for the monitoring of electrophysiological

3 activities in a cell. However, the operation of these methods requires skilled operators.

4 Furthermore, the patch clamp methods could measure an ion flux only at a specific location of a

5 cell membrane rather than the electrical potential of the whole cell membrane, and, thus, it could

6 only monitor the partial intracellular electrical signal pathways.

7 On the other hand, nanoscale devices have been developed to explore the

8 electrophysiological activities of adherent cells with rather easy procedures (Cheng et al., 2014;

9 Li et al., 2013; Spanu et al., 2015). Among the nanoscale devices, many researchers have utilized

10 carbon nanotube-based transistors to monitor the activities of various cells (Sudibya et al., 2009;

11 Tsai et al., 2008; Wang et al., 2007). However, nanoscale devices usually exhibited different

12 characteristics from one device to another, which made it difficult to quantitatively analyze the

13 data measured by nano-devices. Furthermore, the direct growth of cells on devices might affect

14 the characteristics of the nano-devices, resulting in a difficulty in comparing the data measured

15 by different nano-devices.

16 Herein, we report a method for the quantitative electrophysiological monitoring of the

17 antihistamine drug effects on live cells using reusable sensor platforms (RSPs) based on carbon

18 nanotube (CNT) transistors. In this work, HeLa cells were first floated in a solution, and one of

19 the cells was placed on the junction area of a reusable sensor based on a CNT transistor via a

20 microcapillary manipulation for the monitoring of its electrophysiological responses to histamine

21 and anti-histamine drugs. Significantly, for repeated measurements, the measured cell was

22 replaced with a new cell on the same RSP, enabling quantitative evaluation without being

23 suffered from the device-to-device variation of device characteristics. The method was utilized to 
1 quantitatively monitor the electrophysiological responses of HeLa cells to histamine by

2 evaluating the conductance changes of a RSP. These conductance changes were attributed to a

$3 \mathrm{Ca}^{2+}$ influx through ion channels on a HeLa cell membrane due to the activation of H1Rs by

4 histamine. The pretreatments of HeLa cells with anti-histamine drugs such as cetirizine or

5 chlorphenamine reduced a $\mathrm{Ca}^{2+}$ influx into the cells, which indicates that the activation of H1Rs

6 was inhibited by anti-histamine drugs (Mizuguchi et al., 2013). Importantly, for each

7 experimental set, we utilized only a single device to evaluate the activity of H1Rs in multiple

8 HeLa cells, which allowed us to obtain statistically meaningful and quantitative results about the

9 antihistamine drug effects without errors from device-to-device variations. Our work should

10 provide a simple but powerful method for various biomedical applications such as drug

11 screening and pharmaceutical studies at a single-cell-level.

\section{2. Material and methods}

14 2.1. Fabrication of Reusable Sensor Platforms

15 A RSP was fabricated by a method reported in our previous works (Kim et al., 2012; Ta

16 et al., 2014). In brief, glass substrates were soaked into a piranha solution (the 3:1 mixture of a

17 concentrated sulfuric acid solution and a $30 \%$ wt. hydrogen peroxide solution) to remove organic

18 residues on the substrates (Fig. 1a-i). To disperse CNTs, the powder form of CNTs (purchased

19 from Sigma-Aldrich) was sonicated in 1,2-dichlorobenzene $(0.05 \mathrm{mg} / \mathrm{mL})$ for 1 hour. Then, the

20 CNTs suspension was spin-coated on the glass substrates at $5000 \mathrm{rpm}$. The source, drain, and

21 floating electrodes $(\mathrm{Au} / \mathrm{Pd}, 30 \mathrm{~nm} / 10 \mathrm{~nm})$ were fabricated by conventional photolithography

22 processes including a thermal evaporation deposition and a lift-off process. After that, the RSPs

23 were passivated by an aluminum oxide layer $\left(\mathrm{Al}_{2} \mathrm{O}_{3}, 100 \mathrm{~nm}\right)$ using an atomic layer deposition 
1 (ALD) system to eliminate leakage currents and possible effects from other cells during sensing

2 experiments in a liquid environment. A further photolithography step was performed to open

3 junction areas. Finally, the $\mathrm{Al}_{2} \mathrm{O}_{3}$ layer on the junction areas was etched by an $\mathrm{H}_{3} \mathrm{PO}_{4}$ solution

4 (85\% by weight in water) at $90{ }^{\circ} \mathrm{C}$ for 3 minutes (Fig. $1 \mathrm{a}-\mathrm{ii}$ ).

\subsection{Repeated Measurement of Cell Responses Using Reusable Sensor Platforms}

For the measurement of electrophysiological responses of HeLa cells, a RSP was

8 assembled in a live-cell imaging chamber. HeLa cells (purchased from the Korean Cell Line

9 Bank) were cultured on a plate in Dubecco's Modified Eagle Medium (DMEM, Gibco)

10 supplemented with fetal bovine serum $(10 \% \mathrm{v} / \mathrm{v}), \mathrm{L}-$ glutamine $(2 \mathrm{mM})$, penicillin $(100 \mathrm{U} / \mathrm{mL})$,

11 and streptomycin $(100 \mu \mathrm{g} / \mathrm{mL})$ at $37{ }^{\circ} \mathrm{C}$ in an atmosphere of $5 \% \mathrm{CO}_{2}$ for 4 days (Figure 1a-iii).

12 Right before the measurements of the effect of histamine and anti-histamine drugs, HeLa cells

13 were incubated in a fresh $\mathrm{Ca}^{2+}$-free bath solution for 60 minutes. To transfer these cells onto our

14 RSP, the cells were first washed three times with a $\mathrm{Ca}^{2+}-$ free bath solution, then, detached from

15 the plate using a trypsin solution (Figure 1a-iv). A HeLa cell suspension was introduced in the

16 imaging chamber, and the aggregate of HeLa cells was picked up using a microcapillary (Figure

17 1a-v). The aggregate was adjusted to locate a cell on the junction area for the screening of drugs

18 using the RSP (Figure 1a-vi). The source-drain bias $\left(\mathrm{V}_{\mathrm{sd}}\right)$ of $0.1 \mathrm{~V}$ was applied to RSPs during

19 the conductance measurements, and the source-drain currents were monitored by a data

20 acquisition system (National Instruments, NI-9215(A)). To estimate the

21 concentration-dependent effects of histamine on HeLa cells, $200 \mu \mathrm{L}$ of a histamine solution

22 containing $15 \mu \mathrm{M} \mathrm{Ca}^{2+}$ with the range of histamine concentrations from $300 \mathrm{nM}$ to $300 \mathrm{mM}$ was

23 injected into the chamber. For the study of the effects of anti-histamine drugs, cells were 
1 incubated with the various concentrations of anti-histamine drugs (from 10 to $200 \mu \mathrm{M}$ ) for

2 further 15 minutes before the loading of floating cells on a RSP was performed. And then, 200

$3 \mu \mathrm{L}$ of a histamine solution ( $300 \mu \mathrm{M}$, containing $\left.15 \mu \mathrm{M} \mathrm{Ca}^{2+}\right)$ was injected to stimulate the cells.

4

\section{3. Results and discussion}

\section{3.1. Advantage of a RSP}

In a typical experiment, only the junction area including floating electrodes of a RSP was

8 exposed to a single HeLa cell during drug response experiments (Fig. 1a-ii). It allows us to

9 eliminate leakage currents and possible non-specific effects from other cells during sensing

10 experiments in a liquid environment. Fig. 1b shows the optical image of a single HeLa cell

11 placed on a CNT junction area using a microcapillary. Significantly, since HeLa cells were not

12 directly cultured on device surfaces, they did not alter the characteristics of RSPs. Furthermore,

13 the measured cell could be easily removed from the RSP surface, and the used RSP device could

14 be reused for additional measurements with different cells, which allowed us to obtain

15 statistically-meaningful results without suffering from possible errors due to device-to-device

16 variations. Note that, unlike a patch clamp method, we do not need to form a hole or a high

17 resistance seal on a cell membrane using a micropipette, and, thus, our method could be a 18 convenient and non-invasive method. Furthermore, our method could quantitatively monitor

19 electrophysiological signals at a single-cell-level, which would be a significant advantage for 20 biomedical researches and applications.

22 3.2. Characteristics of a RSP 
A topography image of a RSP taken by an atomic force microscopy (AFM) system

2 (MFP-3D, Asylum Research) in a tapping mode shows the junction area of a RSP device with

3 three floating electrodes (Fig. 2a). The dimensions of each floating electrode are $2 \mu \mathrm{m}$ wide and

$410 \mu \mathrm{m}$ long. Moreover, the width of an exposed junction area is $15 \mu \mathrm{m}$, which fits the size of a

5 single HeLa cell, which allowed us to monitor electrophysiological responses at a

6 single-cell-level. Another advantage of our reusable sensor is a high sensitivity, which was

7 enabled by aligned CNTs networks and floating electrodes. Previous works reported that the

8 alignment of CNTs could increase the density of CNTs in a junction area and improve the

9 connectivity between electrodes while reducing lateral connections, which resulted in the

10 significant enhancement of a device transconductance and a sensor sensitivity (Lee et al., 2010;

11 Lee et al., 2009). Besides, the formation of floating electrodes could also enhance the sensitivity

12 of our RSP due to the increased number of Schottky barriers in the devices as reported

13 previously (Kim et al., 2012).

14 Fig. $2 b$ shows the gating effect curve of a RSP obtained by using an $\mathrm{Ag} / \mathrm{AgCl}$ liquid gate

15 electrode as a liquid gate in a $\mathrm{Ca}^{2+}$-free bath solution. A bias voltage between source and drain

16 electrodes was maintained at $0.1 \mathrm{~V}$, while a gate bias voltage $\left(V_{l g}\right)$ was swept from -0.5 to $0.5 \mathrm{~V}$.

17 The source-drain current $\left(I_{d s}\right)$ of RSPs was measured by a semiconductor characterization

18 system (Keithley, 4200, USA). The curve shows a decreasing source-drain current with an

19 increasing gate bias. It implies that our device exhibited $p$-type characteristics. In addition, the

20 current decreased drastically by a small gate bias change, indicating the high sensitivity of our

21 device.

22

23 3.3. $\mathrm{Ca}^{2+}$ influx into HeLa cells 
To confirm a histamine-induced $\mathrm{Ca}^{2+}$ influx into HeLa cells assembled onto our RSP

2 devices, we performed conventional fluorescence $\mathrm{Ca}^{2+}$ assays. HeLa cells were loaded with 2

$3 \mu \mathrm{M}$ fluo-4-AM as a $\mathrm{Ca}^{2+}$ indicator and intracellular calcium changes were measured upon

4 stimulation by histamine (details in Supplementary Information). Throughout the incubation

5 process, the indicator molecules permeated into the cells, which made it possible for us to detect

6 intracellular $\mathrm{Ca}^{2+}$ ions. Fig. $2 c$ and $2 d$ show the histamine responses of HeLa cells cultured on a

7 glass substrate and floating HeLa cells assembled on our RSP device, respectively. Note that, in

8 both of cases, the fluorescence intensity of HeLa cells significantly increased when a $100 \mu \mathrm{M}$

9 histamine solution was injected. These results confirmed that histamine induced $\mathrm{Ca}^{2+}$

10 concentration changes even inside the floating HeLa cells assembled onto our RSP devices

11 (Bristow and Zamani, 1993; Sauve et al., 1991).

\section{3.4. Effect Monitoring of histamine by using a RSP}

14 The changes of $\mathrm{Ca}^{2+}$ concentrations in cells could be mediated by two well-known

15 mechanisms, namely a $\mathrm{Ca}^{2+}$ release from intracellular stores and a $\mathrm{Ca}^{2+}$ influx through

16 specialized channels on a plasma membrane (Berridge, 1997; Streb et al., 1983). Fig. 3a depicts

17 the mechanism of a $\mathrm{Ca}^{2+}$ influx via store-operated calcium channels (SOCCs) and

18 voltage-dependent calcium channels (VDCCs) opened by the histamine stimulation on H1Rs.

19 HeLa cells are known to possess histamine receptors including H1Rs (Mizuguchi et al., 2013;

20 Sauve et al., 1991). In a resting state, ion channels such as SOCCs and VDCCs on a cell

21 membrane are closed. When histamine molecules interact with $\mathrm{H} 1 \mathrm{Rs}, \mathrm{IP}_{3}$ molecules are

22 generated as a second messenger in an intracellular signaling pathway. Subsequently, the

23 activities of $\mathrm{IP}_{3}$ induces $\mathrm{Ca}^{2+}$ release from intracellular stores which mediates a $\mathrm{Ca}^{2+}$ influx 
1 through SOCCs referred to as capacitive $\mathrm{Ca}^{2+}$ entry. In turn, the further entry of $\mathrm{Ca}^{2+}$ is promoted

2 through VDCCs which are opened by membrane depolarization (Barajas et al., 2008; Dai and

3 Zhang, 2002; Nemeth and Kurucz, 2005). Since $\mathrm{Ca}^{2+}$ flows into a cell through the opening of ion

4 channels, a negative potential on the extracellular side of a plasma membrane increases (Fig. 3b).

5 Note that the electric currents of our RSPs increase with a negative gate bias (Fig. 2b). Thus, the

6 stimulation of HeLa cells by histamine can cause the conductance increase of RSPs, which could

7 be used to evaluate the interaction between ligands and receptors on a cell membrane.

8 Fig. 3c shows real-time relative conductance changes measured by a floating

9 electrode-based RSP with or without a HeLa cell during the injection of histamine. The relative

10 conductance level of the RSP with a HeLa cell increased by $~ 10 \%$ when a histamine solution

11 was injected, while that of the RSP without a cell exhibited no response. The conductance

12 increase by the histamine injection could be attributed to the activity initiated by H1Rs in the

13 HeLa cell. Once histamine molecules bound to H1Rs, $\mathrm{Ca}^{2+}$ flowed into the cell, which generated

14 a temporary negative potential in a gap between the cell and the CNT junction area of the RSP

15 (Fig. 3b). Note that since our RSP exhibited $p$-type characteristics, the increase of a negative

16 potential would cause the increase of its conductance (Ta et al., 2014). The increased

17 conductance was recovered back to the original value after 50 seconds. This conductance

18 recovery was probably due to the repolarization process of the cell and the charge balance of a

19 bath solution. As reported previously, the influx of $\mathrm{Ca}^{2+}$, which increased positive charges within

20 a cell, was followed by the outflux of potassium ions $\left(\mathrm{K}^{+}\right)$from the cell (Benarroch, 2010).

21 Moreover, cations in a bath solution could diffuse into the gap to neutralize excess negative

22 charges. Both of these factors probably resulted in the conductance recovery of the RSP after the

23 response of the histamine injection. This data clearly indicates that our RSPs could detect the 
1 electrophysiological effects of histamine on HeLa cells. Significantly, since our method just

2 measure the surrounding potential changes without damaging cells, it could be applied for the

3 study of the electrophysiological responses of various cell lines in a non-invasive manner.

4 The responses of a HeLa cell to histamine could be quantified by the relative conductance

5 changes of our RSP. Fig. 3d shows the conductance responses of a RSP by the stimulation of

6 different concentration histamine solutions in the range from $100 \mathrm{nM}$ to $100 \mathrm{mM}$. To confirm the

7 repeatability of our RSP, we carried out measurements three times for each concentration of

8 histamine using the same RSP (Fig. S1). The dose-response curve was fitted by a Hill equation

9 written as (Bristow and Zamani, 1993)

$$
\Delta G / G_{0}=\Delta G / G_{0 \max } \frac{C^{n}}{\left(E C_{50}\right)^{n}+C^{n}}
$$

Here, $\Delta G / G_{0}$ and $\Delta G / G_{0 \max }$ are a relative conductance change and the maximum value of

12 relative conductance changes, respectively. $C$ and $E C_{50}$ are the concentration of histamine in a

13 solution and the concentration of histamine giving a half-maximal relative conductance change,

14 respectively. $n$ is a Hill coefficient. In case of drug screening experiments, the potency of

15 specific drugs can be represented by the values of $\mathrm{p} E C_{50}$ which is defined as $-\log _{10}\left(E C_{50}\right)$. The

16 fitting analysis on our data shows that the estimated value of $\mathrm{p} E C_{50}$ by histamine stimulation was

$17 \sim 5.78 \pm 0.23$, which was similar to a previously-reported value measured by a fluorescent

18 method (Bootman et al., 1992). Also, note that when the concentrations of histamine solutions

19 was larger than $10 \mu \mathrm{M}$, the cell responses saturated and have similar values for different

20 concentration histamine solutions, which is consistent with previous works (Bootman et al.,

21 1992; Bristow and Zamani, 1993; Volpi and Berlin, 1988). It should be noted that such a

22 statistically-meaningful quantitative measurement was made possible because our method allow 
1 us to perform repeat measurements for multiple cells using a single RSP device and thus to

2 minimize possible errors from device-to-device variations of its characteristics.

4 3.5. Effect Monitoring of anti-histamine drugs by using RSPs

5 Fig. 4a describes the mechanism of anti-histamine drug effect on a $\mathrm{Ca}^{2+}$ influx into a

6 HeLa cell. In this work, we evaluated the effects of cetirizine and chlorphenamine as anti-

7 histamine drugs which were known as inverse agonists. Once inverse agonists bind with H1Rs,

8 the H1Rs are converted to inactive forms, and the receptor activity of cells is down-regulated

9 (Mizuguchi et al., 2013). Thus, the activation of H1Rs by histamine is degraded, resulting in the

10 decrease of a $\mathrm{Ca}^{2+}$ influx through SOCCs into the cells. In turn, $\mathrm{a} \mathrm{Ca}^{2+}$ influx via the opening of

11 VDCCs should be decreased due to the reduced membrane depolarization. Thus, the quantitative

12 effects of anti-histamine drugs to HeLa cells can be evaluated by monitoring the membrane

13 potential change caused by the $\mathrm{Ca}^{2+}$ influx into the cells.

14 Fig. 4b shows the real-time electrophysiological responses of HeLa cells pretreated with

15 or without cetirizine, one of the anti-histamine drugs. To study the effect of cetirizine, HeLa cells

16 were incubated with a $\mathrm{Ca}^{2+}-$ free bath solution including $50 \mu \mathrm{M}$ cetirizine for 15 minutes before

17 the cells were transferred and assembled on a RSP. To trigger a $\mathrm{Ca}^{2+}$ influx into cells, a bath

18 solution with histamine was injected so that the final concentration of histamine was $100 \mu \mathrm{M}$.

19 The relative conductance change of the RSP with the HeLa cell pretreated with cetirizine was

$20 \sim 5 \%$, which was significantly smaller than that of the RSP with a non-pretreated HeLa cell

21 ( 13\%). This result indicates that cetirizine worked as an anti-histamine drug on the HeLa cells

22 assembled on the RSP, and our method can be utilized to measure the effect of anti-histamine

23 drugs in real time. 
We could also quantitatively monitor the electrophysiological effects of different

2 anti-histamine drugs with various concentrations (Fig. 4c). Here, HeLa cells were incubated

3 with bath solutions including cetirizine or chlorphenamine with various concentrations ranging

4 from 10 to $200 \mu \mathrm{M}$. Then, the response of individual HeLa cells by the injection of $100 \mu \mathrm{M}$

5 histamine was measured using a single RSP. For a reliable statistical analysis, we repeated

6 measurements three times for each anti-histamine drug concentration using the same RSP.

7 Dose-response curves showed the drastic decrease of the relative conductance changes of a RSP

8 for HeLa cells pretreated with chlorphenamine. Importantly, the relative conductance changes of

9 a RSP for HeLa cells pretreated with cetirizine were smaller than those with chlorphenamine.

10 The result is also consistent with previous reports showing that chlorphenamine was a stronger

11 inverse agonist than cetirizine (Christophe et al., 2003; Mizuguchi et al., 2013).

12 To quantitatively estimate the effect of anti-histamine drugs, the results were analyzed

13 by a Hill equation for inhibitors like

$$
\Delta G / G_{0}=\Delta G / G_{0 \max }+\left(\Delta G / G_{0 \min }-\Delta G / G_{0 \max }\right) \frac{A^{n}}{\left(I C_{50}\right)^{n}+A^{n}}
$$

Here, $\Delta G / G_{0 \min }$ is the minimum value of relative conductance changes. $A$ and $I C_{50}$ are the

16 concentration of an anti-histamine drug in a solution and that of an anti-histamine drug giving

17 a half-maximal relative conductance change, respectively. Anti-histamine drugs are 'inhibition'

18 drugs whose role is blocking the binding of histamine to receptors. In this case, the potency of

19 such drugs can be evaluated by a $\mathrm{p} I C_{50}$ value which is defined as $-\log _{10}\left(I C_{50}\right)$ and representing

20 an inhibition efficiency rather than a binding efficiency. By fitting the data, $\mathrm{p} I C_{50}$ values for

21 cetirizine and chlorphenamine were directly calculated from dose-response curves to be 4.70

22 and 5.77, respectively. These pIC50 values quantitatively indicate that the measured potency of 
1 chlorphenamine was higher than that of cetirizine as reported previously (Christophe et al.,

2 2003). Significantly, previous works show that chlorphenamine inhibited the activity of H1Rs

3 with $\mathrm{p} I C_{50}$ values in the range of $3.86-6.28$, which is consistent with our measurement results

4 (Markwardt et al., 1996; Sakuta, 1994; Salata et al., 1995). This result supports the validity of

5 our method. Furthermore, the measured response data in Fig. $4 \mathrm{c}$ can be utilized to estimate the

6 quantity of H1Rs which were still active with anti-histamine drugs. For example, the HeLa cells

7 pretreated with $10 \mu \mathrm{M}$ chlorphenamine exhibited a relative conductance change of $\sim 40 \%$

8 compared with the response of non-pretreated cells. It implies that $\sim 60 \%$ of H1Rs on a cell

9 membrane shifted to inactive forms by chlorphenamine, which was consistent with previous

10 results measured by conventional methods (Mizuguchi et al., 2013).

11 To fully appreciate our method, the Cheng-Prusoff equation was used to estimate

12 inhibitor constants, $K_{i}$, which are indicators for the efficiency of drugs (Lazareno and Birdsall, 13 1993).

$$
K_{i}=\frac{I C_{50}}{1+\frac{C}{E C_{50}}}
$$

$15 \mathrm{p} K_{i}$ values, defined as $-\log _{10}\left(K_{i}\right)$, for cetirizine and chlorphenamine were calculated from 16 the Cheng-Prusoff equation to be 6.49 and 7.56, respectively. These results clearly show that our 17 method can be utilized to quantitatively evaluate the effect of anti-histamine drugs. Considering 18 that the statistically-meaningful quantitative measurement of drug effects using high19 performance nanoscale devices have been extremely difficult due to rather large device-to-device 20 variations of its characteristics, our strategy can be a significant breakthrough in the various 
1 applications of nanoscale devices such as drug screenings and electrophysiological study of cell

2 activities.

4 4. Conclusions

In summary, we report a strategy using a single RSP device to quantitatively monitor the

6 electrophysiological responses of multiple individual cells to histamine and anti-histamine

7 drugs. Here, we could repeatedly measure the real-time response of HeLa cells to histamine

8 drugs quantitatively using the same RSP device. Results have showed that our method enables

9 the statistically-meaningful quantitative evaluations without suffering from the errors by the

10 device-to-device variations of sensor characteristics. Using this method, we demonstrated the

11 quantitative evaluation of the effect of antihistamine drugs such as cetirizine and chlorphenamine

12 and found that chlorphenamine had a better efficacy than cetirizine as reported previously

13 (Christophe et al., 2003). Since our strategy takes an advantage of high-performance nanoscale

14 devices while still enabling the statistically-meaningful evaluations, it can be a powerful tool for 15 various applications such as drug screening and therapeutic monitoring.

\section{Acknowledgements}

18 This work was supported by Bio Nano Health-Guard Research Center funded by the

19 Ministry of Science, ICT \& Future Planning (MSIP) of Korea as Global Frontier Project (No.

20 2013M3A6B2078961). SH also acknowledges the support from the MSIP (Nos.

21 2014M3A7B4051591) and the European Research Council (ERC) under the European Union's

22 Horizon 2020 research and innovation programme (grant agreement No 682286). 


\section{References}

2 Akdis, C.A., Blaser, K., 2003. J. Allergy Clin. Immunol. 112(1), 15-22.

3 Barajas, M., Andrade, A., Hernandez-Hernandez, O., Felix, R., Arias-Montano, J.A., 2008. J.

$4 \quad$ Neurosci. Res. 86(15), 3456-3468.

5 Benarroch, E.E., 2010. Neurology 75(16), 1472-1479.

6 Berridge, M.J., 1997. J. Physiol. 499(2), 291-306.

7 Bootman, M.D., Berridge, M.J., Taylor, C.W., 1992. J. Physiol. 450, 163-178.

8 Bristow, D.R., Zamani, M.R., 1993. Br. J. Pharmacol. 109(2), 353-359.

9 Cheng, J., Wu, L., Du, X.W., Jin, Q.H., Zhao, J.L., Xu, Y.S., 2014. J. Microelectromech. Syst. $10 \quad 23(6), 1311-1317$.

11 Christophe, B., Carlier, B., Gillard, M., Chatelain, P., Peck, M., Massingham, R., 2003. Eur. J. 12 Pharmacol. 470(1-2), 87-94.

13 Dai, Y., Zhang, J.H., 2002. Am. J. Physiol. Heart Circ. Physiol. 282(4), H1427-1436.

14 Jutel, M., Akdis, M., Akdis, C.A., 2009. Clin. Exp. Allergy 39(12), 1786-1800.

15 Kim, B., Lee, J., Namgung, S., Kim, J., Park, J.Y., Lee, M.S., Hong, S., 2012. Sensors Actuators

16 B: Chem. 169, 182-187.

17 Lazareno, S., Birdsall, N.J.M., 1993. Br. J. Pharmacol. 109(4), 1110-1119.

18 Lee, M., Lee, J., Kim, T.H., Lee, H., Lee, B.Y., Park, J., Jhon, Y.M., Seong, M.J., Hong, S., 19 2010. Nanotechnology 21(5), 055504.

20 Lee, M., Noah, M., Park, J., Seong, M.J., Kwon, Y.K., Hong, S., 2009. Small 5(14), 1642-1648.

21 Li, B.R., Hsieh, Y.J., Chen, Y.X., Chung, Y.T., Pan, C.Y., Chen, Y.T., 2013. J. Am. Chem. Soc.

22 135(43), 16034-16037.

23 MacGlashan, D., Jr., 2003. J. Allergy Clin. Immunol. 112(4 Suppl), S53-59. 
1 Markwardt, K.L., Magnino, P.E., Pang, I.H., 1996. Exp. Eye Res. 62(5), 511-520.

2 Mizuguchi, H., Ono, S., Hattori, M., Sasaki, Y., Fukui, H., 2013. Int. Immunopharmacol. 15(3), $3 \quad 539-543$.

4 Molina-Hernandez, A., Diaz, N.F., Arias-Montano, J.A., 2012. J. Neurochem. 122(5), 872-882.

5 Negulyaev Yu, A., Savokhina, G.A., Vedernikova, E.A., 1993. Gen. Physiol. Biophys. 12(1), 19625.

7 Nemeth, K., Kurucz, I., 2005. Biochem. Pharmacol. 69(6), 929-940.

8 Sakuta, H., 1994. Eur. J. Pharmacol. 266(1), 99-102.

9 Salata, J.J., Jurkiewicz, N.K., Wallace, A.A., Stupienski, R.F., 3rd, Guinosso, P.J., Jr., Lynch, 10 J.J., Jr., 1995. Circ. Res. 76(1), 110-119.

11 Sauve, R., Diarra, A., Chahine, M., Simoneau, C., Morier, N., Roy, G., 1991. Cell Calcium 12(2$123), 165-176$.

13 Schneider, E., Rolli-Derkinderen, M., Arock, M., Dy, M., 2002. Trends Immunol. 23(5), 25514263.

15 Spanu, A., Lai, S., Cosseddu, P., Tedesco, M., Martinoia, S., Bonfiglio, A., 2015. Sci. Rep. 5, 168807.

17 Streb, H., Irvine, R.F., Berridge, M.J., Schulz, I., 1983. Nature 306(5938), 67-69.

18 Sudibya, H.G., Ma, J., Dong, X., Ng, S., Li, L.J., Liu, X.W., Chen, P., 2009. Angew. Chem. Int. 19 Ed. Engl. 48(15), 2723-2726.

20 Ta, V.T., Park, J., Park, E.J., Hong, S., 2014. ACS Nano 8(3), 2206-2213.

21 Tsai, C.C., Yang, C.C., Shih, P.Y., Wu, C.S., Chen, C.D., Pan, C.Y., Chen, Y.T., 2008. J. Phys.

22 Chem. B 112(30), 9165-9173.

23 Volpi, M., Berlin, R.D., 1988. J. Cell Biol. 107(6), 2533-2539. 
1 Wang, C.W., Pan, C.Y., Wu, H.C., Shih, P.Y., Tsai, C.C., Liao, K.T., Lu, L.L., Hsieh, W.H.,

2 Chen, C.D., Chen, Y.T., 2007. Small 3(8), 1350-1355.

3

4 
a) i)

\section{Glass Substrate}

Glass Substrate

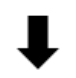

ii)

\section{Floating Electrode}

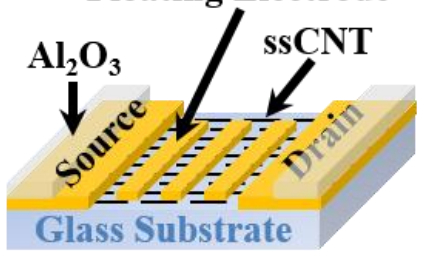

Reusable Sensor Platform

v)

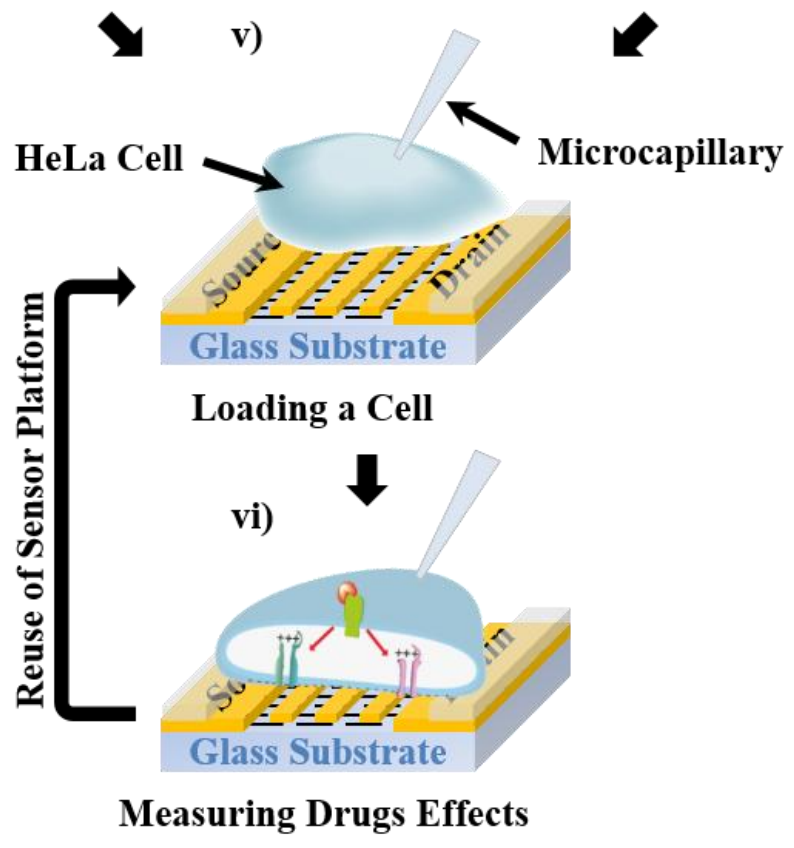

iii)

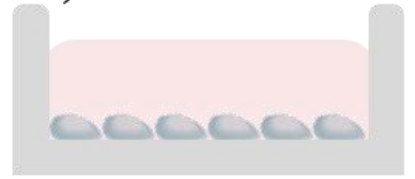

Cell Culture

$\checkmark$

iv)

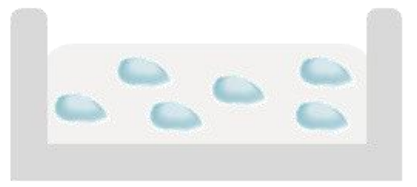

Cell Detachment

b)

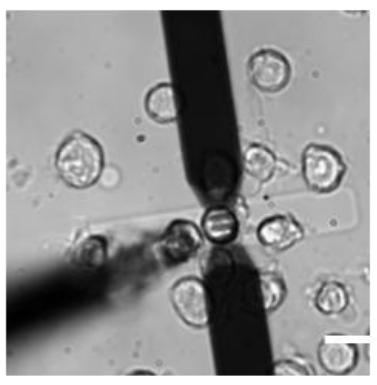

c)<smiles>NCCc1cnc[nH]1</smiles>

Histamine<smiles>CN(C)CCC(c1ccc(Cl)cc1)c1ccccn1</smiles>

Chlorphenamine<smiles>O=C(O)COCCN1CCN(C(c2ccccc2)c2ccc(Cl)cc2)CC1</smiles>

Cetirizine

3 Fig. 1. Schematic diagram depicting an experimental procedure and the molecular formulas of

4 chemicals used in experiments. (a) Schematic diagram of an experimental procedure: (i)

5 preparation of a clean glass substrate; (ii) fabrication of a reusable sensor platform via

6 conventional photolithography processes; (iii) culturing of HeLa cells on a plate; (iv) detachment 
1 of the HeLa cells using a trypsin solution; (v) loading of a floating HeLa cell on the RSP; (vi)

2 monitoring of the electrophysiological responses of the cell to drugs using the RSP. Steps (v) and

3 (vi) can be repeated for different cells using the same RSP device. (b) Microscopic image

4 showing a Hela cell transferred to the junction area of a RSP using a microcapillary. The scale

5 bar represents $20 \mu \mathrm{m}$. (c) Chemical formulas of histamine, chlorphenamine, and cetirizine. 
a)

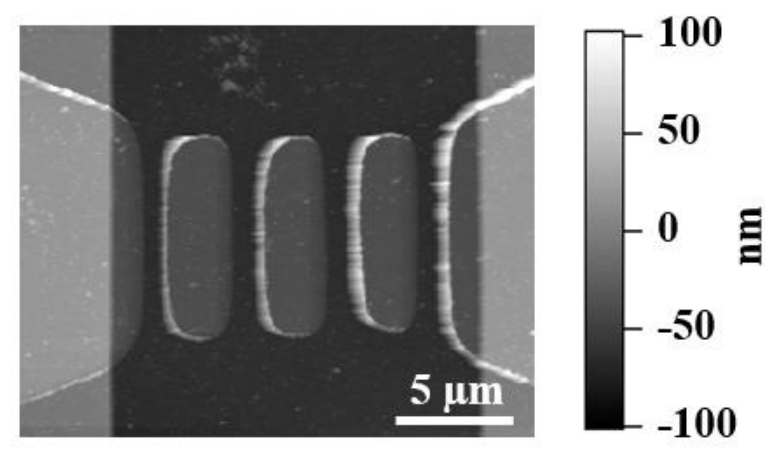

c)

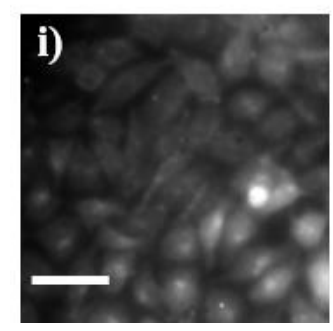

b)

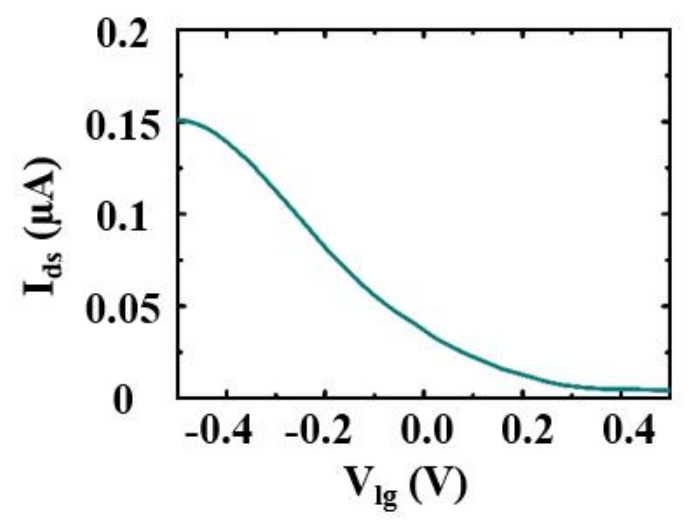

d)

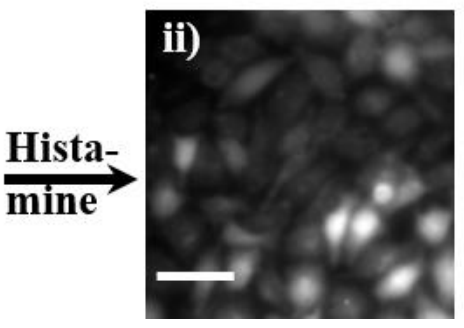

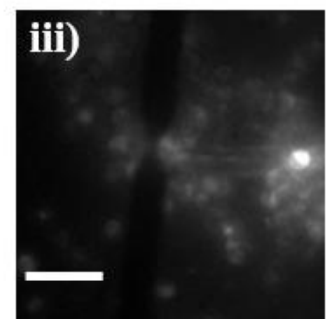

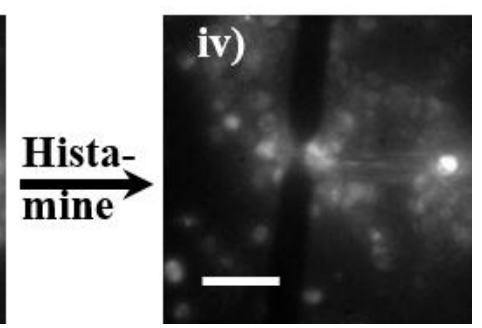

2 Fig. 2. Characterization of a reusable sensor platform (RSP) based on carbon nanotubes. (a)

3 AFM topography image of a RSP with three floating electrodes connected by carbon nanotube

4 networks. Individual floating electrodes have the dimensions of a $2 \mu \mathrm{m}$ width and a $10 \mu \mathrm{m}$

5 length. (b) Liquid gating effect of a RSP. Here, an $\mathrm{Ag} / \mathrm{AgCl}$ electrode was used as a liquid gate

6 electrode, and a gate bias was swept from -0.5 to $0.5 \mathrm{~V}$ with the source-drain bias of $0.1 \mathrm{~V}$. (c)

7 Fluorescent images of HeLa cells cultured on a glass substrate were taken before (i) and after (ii)

8 the injection of histamine. (d) Fluorescent images of HeLa cells assembled on a RSP were taken

9 before (iii) and after (iv) the injection of histamine. The scale bars represent $50 \mu \mathrm{m}$. 

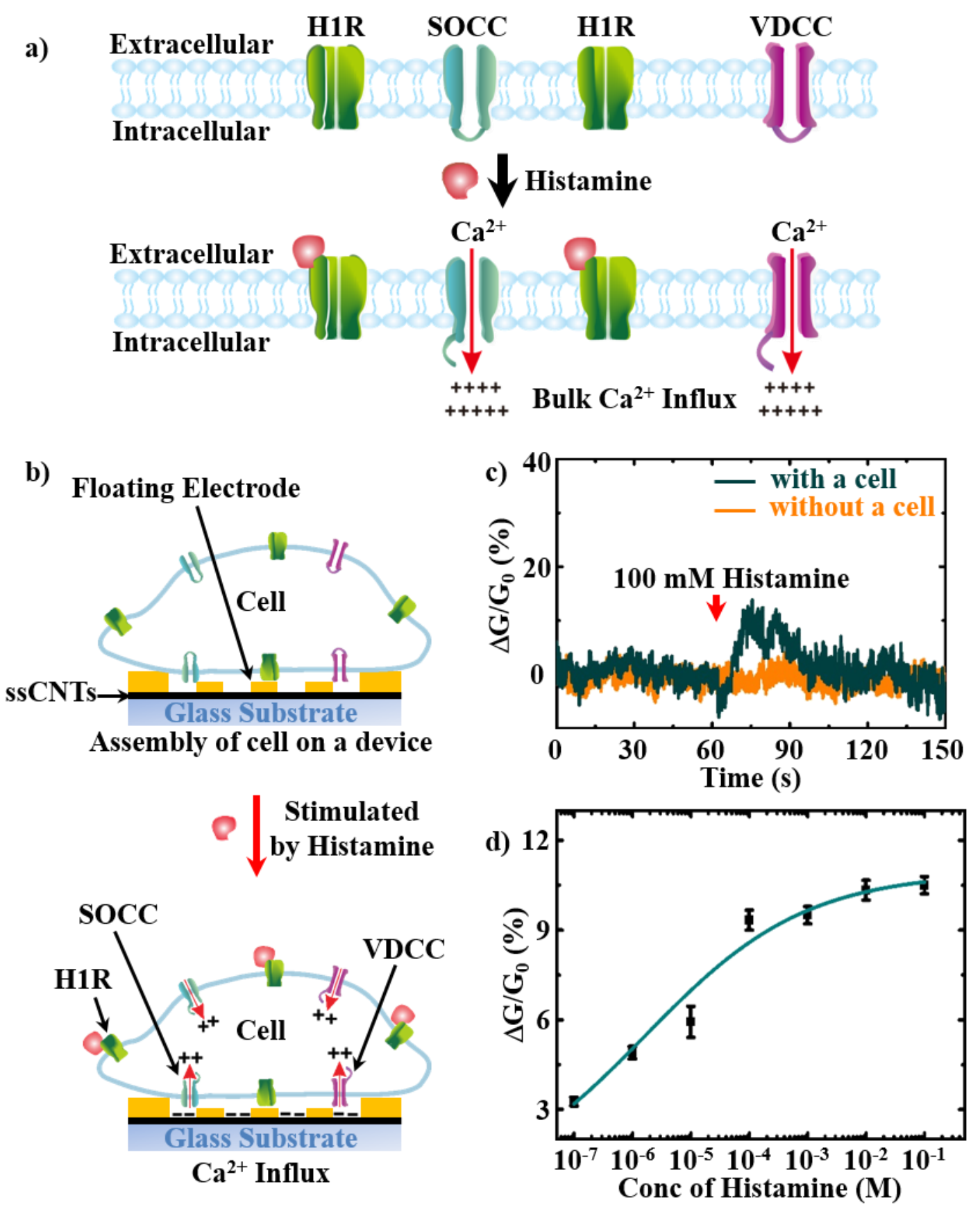

2 Fig. 3. Quantitative electrophysiological monitoring of the effect of histamine drug on HeLa 3 cells. (a) Schematic drawing sketching the mechanism of a $\mathrm{Ca}^{2+}$ influx via the activations of

4 SOCCs and VDCCs by histamine. (b) Schematic diagram showing the sensing mechanism of our 5 RSP device by the histamine stimulation on a cell. (c) Real-time conductance changes measured 
1 by a RSP with (dark cyan line) and without a HeLa cell (orange line) during the injection of 100

$2 \mathrm{mM}$ histamine. (d) Relative conductance change of the RSP in response to the histamine with

3 different concentrations. A dose-response curve was fitted by a Hill equation (solid line). All

4 measurements were performed using a single RSP device. Data are expressed as means \pm SEM

5 (standard error of the mean), $(n=3)$.

6 
a)

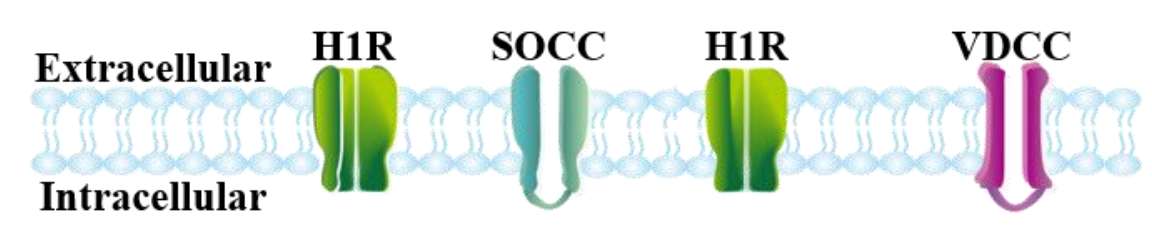

\section{$2 \sqrt{ }$ Antihistamines}

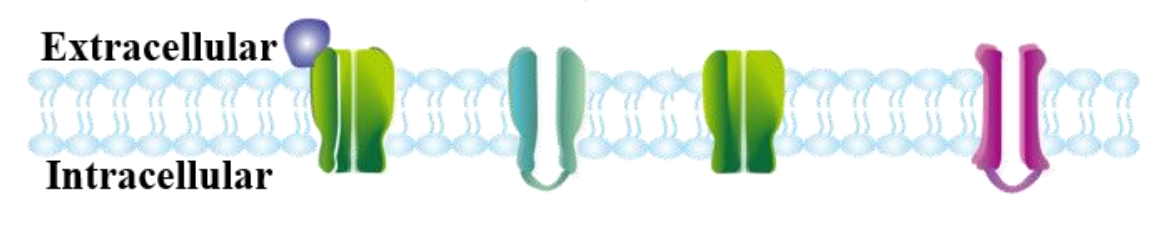

\section{$\checkmark \downarrow$ Histamine}
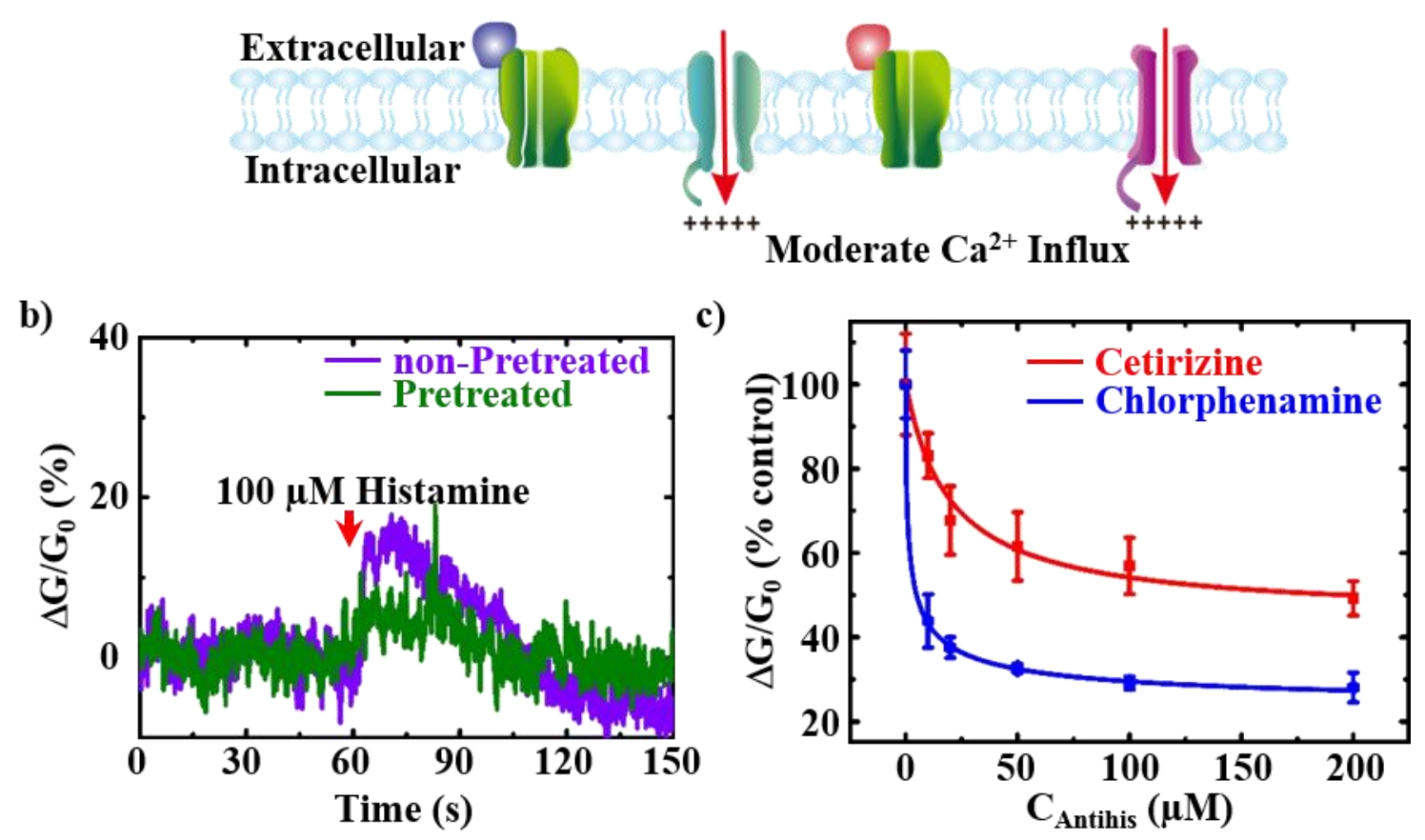

2 Fig. 4. Quantitative electrophysiological monitoring of antihistamine drug effects using RSP

3 devices. All electrophysiological measurements for each anti-histamine drug were performed

4 using a single RSP device. (a) Schematic diagram of the effect of an anti-histamine drug on a

$5 \mathrm{Ca}^{2+}$ influx into a HeLa cell. (b) Real-time electrophysiological responses of cetirizine pretreated

6 (marker by "Pretreated", green) and non-pretreated (marker by "non-Pretreated", violet) HeLa

7 cells to the injection of $100 \mu \mathrm{M}$ histamine. (c) Modulation of a $\mathrm{Ca}^{2+}$ influx into HeLa cells by the 
1 various concentrations of anti-histamine drugs. HeLa cells were pretreated with the solutions of

2 cetirizine or chlorphenamine with various concentrations in the range of $10-200 \mu \mathrm{M}$ before the

3 injection of $100 \mu \mathrm{M}$ histamine. Data are expressed as means \pm SEM (standard error of the mean), $4 \quad(n=3)$. 